\title{
THE SARCOPLASMIC RETICULUM PLAYS A MAJOR ROLE IN ISOMETRIC CONTRACTION IN ATRIAL MUSCLE OF YELLOWFIN TUNA
}

\author{
H. A. SHIELS ${ }^{1, *}$, E. V. FREUND ${ }^{2}$, A. P. FARRELL ${ }^{1}$ AND B. A. BLOCK ${ }^{2}$ \\ ${ }^{1}$ Simon Fraser University, Department of Biological Sciences, 8888 University Drive, Burnaby, British Columbia, \\ Canada V5A 1 S6 and ${ }^{2}$ Hopkins Marine Station, Stanford University, Pacific Grove, CA 93950, USA \\ *e-mail: hollys@sfu.ca
}

Accepted 7 January; published on WWW 9 March 1999

\begin{abstract}
Summary
We used an isometric muscle preparation to test the hypothesis that yellowfin tuna Thunnus albacares utilize the intracellular $\mathrm{Ca}^{2+}$ storage sites of the sarcoplasmic reticulum (SR) during routine contractions. Ryanodine (a blocker of SR $\mathrm{Ca}^{2+}$ release) reduced the force of contraction by

force development at physiological contraction frequencies. Further, we suggest that, by using intracellular $\mathrm{Ca}^{2+}$ cycling, the yellowfin tuna is able to increase the maximum contraction frequency of its cardiac muscle beyond that of most other fishes.
\end{abstract} approximately $50 \%$ and the rates of contraction and relaxation by $60 \%$ in yellowfin tuna atrium. High levels of adrenaline were unable to ameliorate the effects of ryanodine. We conclude that the $\mathrm{SR}$ is active in contributing $\mathrm{Ca}^{2+}$ to
Key words: yellowfin tuna, Thunnus albacares, atrium, muscle, adrenaline, ryanodine, force-frequency, temperature, heart.

\section{Introduction}

Maximal heart rates of $130-140$ beats min $^{-1}$ have been measured in yellowfin tuna (Thunnus albacares) (Brill, 1987; Farrell et al., 1992; Keen et al., 1995). These heart rates slightly exceed the suggested upper limit to contraction frequency of 120 beats $\mathrm{min}^{-1}$ observed for most fish (Farrell, 1991). Likewise, skipjack tuna (Katsuwonus pelamis) have maximum heart rates of 154-191 beats min $^{-1}$ (Brill, 1987; Farrell et al., 1992; Keen et al., 1995). These findings suggest differences between cardiac excitation-contraction coupling in tuna and other fishes.

One possible explanation for the exceptional maximum heart rates in tuna is the role of intracellular $\mathrm{Ca}^{2+}$ cycling during excitation-contraction coupling. In cardiac cells, mammals cycle $\mathrm{Ca}^{2+}$ between the intracellular $\mathrm{Ca}^{2+}$ stores of the sarcoplasmic reticulum (SR) and the myofilaments. However, despite the central role of the SR in mammalian excitation-contraction coupling, there exists a graded dependence on SR $\mathrm{Ca}^{2+}$ release which changes with species, developmental stage and regionally within the heart. For example, adult rabbit ventricle is less dependent on $\mathrm{SR} \mathrm{Ca}^{2+}$ release than that of adult rat (Bers, 1991); within a species, neonate hearts are less dependent on SR $\mathrm{Ca}^{2+}$ than adult hearts, and the atrium is more SR-dependent than the ventricle (Bers, 1991). Unlike mammals, most fish cycle extracellular $\mathrm{Ca}^{2+}$ back and forth across the cell membrane (sarcolemma) between the extracellular space and the myofilaments with each beat. Therefore, the mode of excitation-contraction coupling in fish may result in longer diffusional distances for $\mathrm{Ca}^{2+}$ movement which, in turn, may compromise maximum contraction frequency. Skipjack tuna, which have relatively high maximum contraction frequencies compared with those of other fish, utilize both intra- and extracellular $\mathrm{Ca}^{2+}$ cycling to satisfy the $\mathrm{Ca}^{2+}$ requirements of the myofilaments (at $25^{\circ} \mathrm{C}$; Keen et al., 1992). Thus, $\mathrm{Ca}^{2+}$ cycling during excitation-contraction coupling in skipjack tuna appears to be intermediate between traditional 'fish' and 'mammal' models.

Although most teleost hearts do not routinely use SR $\mathrm{Ca}^{2+}$ (Driedzic and Gesser, 1988), rainbow trout (Oncorhynchus mykiss) ventricles demonstrate increased SR involvement at temperatures near their upper incipient lethal temperature $\left(23-25^{\circ} \mathrm{C}\right.$; Black, 1953) and at subphysiological contraction frequencies (Hove-Madsen, 1992; Keen et al., 1994; Shiels and Farrell, 1997). Thus, the ability to utilize $\mathrm{SR} \mathrm{Ca}^{2+}$ appears to be both frequency- and temperature-dependent. Indeed, the temperature-dependency of SR utilization in fish may stem from the temperature-dependency of the $\mathrm{SR} \mathrm{Ca}^{2+}$-release channel itself. In mammalian cardiac muscle, an acute decrease in temperature increases the open probability of the SR $\mathrm{Ca}^{2+}$ release channel (Bers, 1987, 1989; Sitsapesan et al., 1991), thus rendering the SR ineffective in sequestering and releasing $\mathrm{Ca}^{2+}$ during contraction. The lack of SR involvement during excitation-contraction coupling in most fish hearts may therefore reflect the fact that most studies are conducted between 5 and $15{ }^{\circ} \mathrm{C}$ where there may be cold-induced opening of the SR Ca ${ }^{2+}$-release channel (Tibbits et al., 1992). Conversely, the involvement of SR $\mathrm{Ca}^{2+}$ during force development in skipjack tuna may simply reflect the 
experimental temperature of $25^{\circ} \mathrm{C}$. However, the effect of temperature on $\mathrm{SR} \mathrm{Ca}^{2+}$ release during excitation-contraction coupling has not been examined in tuna hearts. Therefore, the purpose of the present study was to investigate how acute, physiological temperature change affects the contribution of SR $\mathrm{Ca}^{2+}$ during force development in the atrium of yellowfin tuna under physiological levels of adrenergic stimulation. Since $\mathrm{Ca}^{2+}$ cycling has been implicated in contributing to the elevated maximal heart rates in tuna, the experiments were conducted over a range of pacing frequencies from sub$(0.2 \mathrm{~Hz})$ to superphysiological $(3.5 \mathrm{~Hz})$.

\section{Materials and methods}

\section{Fish origin and care}

Yellowfin tuna Thunnus albacares (Bonaterre) were caught off the coast of California in September 1996 and transferred to the Tuna Research and Conservation Center, Pacific Grove, CA, USA, as described by Altringham and Block (1997). Fish were maintained for more than 1 year in tanks $10 \mathrm{~m}$ in diameter and $2 \mathrm{~m}$ deep. Sea water was recirculated, filtered, aerated and maintained at $20 \pm 0.5^{\circ} \mathrm{C}$. Fish were fed a diet of fish and squid three times per week, at approximately $115 \mathrm{~kJ} \mathrm{~kg}^{-1} \mathrm{day}^{-1}$.

\section{Tissue preparation}

Fish $(4.99 \pm 0.13 \mathrm{~kg})$ were netted from the holding tanks and killed by cervical dislocation. The heart was quickly excised and placed in ice-cooled, oxygenated physiological saline (containing, in $\mathrm{moll}^{-1}, \mathrm{NaCl}, 175.7 ; \mathrm{KCl}, 7 ; \mathrm{CaCl}_{2}, 1.9$; $\mathrm{MgCl}_{2}, 1.1$; sodium pyruvate, 10 ; Hepes, $10 ; \mathrm{pH} 7.8$ at $25^{\circ} \mathrm{C}$ ). The atrium $(1.89 \pm 0.11 \mathrm{~g})$ was isolated and cut lengthwise to expose the lumen. Four individual trabeculae were dissected out with the aid of a dissecting microscope and hung between an isometric force transducer (Kulite Semiconductors, Leonia, NJ, USA) and a fixed post, in an oxygenated, water-jacketed organ bath (described in detail by Shiels and Farrell, 1997). The organ bath was maintained at $15^{\circ} \mathrm{C}, 18^{\circ} \mathrm{C}$ or $25^{\circ} \mathrm{C}$. The preparation was lengthened to remove slack and left for $30 \mathrm{~min}$ before stimulation. The muscle was then stimulated at $1.0 \mathrm{~Hz}$, and muscle length $L$ was adjusted to maximize force production (i.e. such that the preparation was operating on the plateau of the length-tension curve), defined as $L_{\text {max }}$. Trabeculae were left to stabilize at $L_{\max }$ for a minimum of $30 \mathrm{~min}$. Stimulation was achieved using a Harvard Student Stimulator (Harvard Apparatus Ltd, Edenbridge, Kent, UK) delivering current pulses $(20 \mathrm{~V}, 10 \mathrm{~ms}$ duration) via platinum plate electrodes positioned on either side of the muscle. Signals from the transducers were displayed on a Windograf digital oscilloscope (Gould, Cleveland, OH, USA) and stored to disk for later analysis.

\section{Experimental protocol}

The experiments were designed to test the acute effects of temperature and adrenaline on the contribution of SR $\mathrm{Ca}^{2+}$ during force development in yellowfin atrial muscle. The degree of involvement of the SR in force production was assessed using ryanodine, a specific and irreversible ligand for the $\mathrm{Ca}^{2+}$-release channel of the $\mathrm{SR}$. When ryanodine is applied to muscle in the micromolar range $\left(10 \mu \mathrm{moll}^{-1}\right)$, as in the present study, it locks the SR $\mathrm{Ca}^{2+}$-release channel closed, rendering it ineffective in contributing $\mathrm{Ca}^{2+}$ to force production (Rousseau et al., 1987). Tissue sensitivity to ryanodine is therefore considered to reflect the dependence of contractility on $\mathrm{Ca}^{2+}$ released from intracellular stores. Experiments were conducted at $15^{\circ} \mathrm{C}, 18^{\circ} \mathrm{C}$ or $25^{\circ} \mathrm{C}$ to investigate the temperature-dependency of the ryanodine response. Because adrenaline is present at nanomolar concentrations in the circulation of resting fish (Milligan et al., 1989), and because it has been shown to preserve cardiac tonus in situ (Farrell et al., 1986; Graham and Farrell, 1989; Davie and Farrell, 1991) and in vitro (Shiels and Farrell, 1997), we utilized a tonic level $\left(1 \mathrm{nmol}^{-1}\right)$ of adrenergic stimulation in all experiments. In rainbow trout, maximal $\left(10 \mu \mathrm{moll}^{-1}\right)$ adrenergic stimulation overwhelms the relative importance of the intracellular (SR) $\mathrm{Ca}^{2+}$ contribution to force production by dramatically increasing the peak force production of isolated ventricular muscle, even after it has been treated with ryanodine and irrespective of temperature (Shiels and Farrell, 1997). We therefore also employed a maximal level of adrenergic stimulation $\left(1 \mu \mathrm{moll}^{-1}\right)$ to observe its effect on the relative importance of SR and sarcolemma $\mathrm{Ca}^{2+}$ flux during force development in yellowfin tuna atrium.

Each experiment consisted of three force-frequency trials performed sequentially on the same trabeculae: (1) with a low adrenaline concentration, (2) with low adrenaline and ryanodine concentrations, and (3) with high adrenaline and ryanodine concentrations. In each force-frequency trial, stimulation frequency was increased from 0.2 to $0.5 \mathrm{~Hz}$ and then to $3.5 \mathrm{~Hz}$ in $0.5 \mathrm{~Hz}$ increments. Force, time to peak tension, time to $50 \%$ relaxation and the rates $(\mathrm{d} f / \mathrm{d} t)$ of contraction and relaxation were measured at each frequency. After each change in stimulation frequency, the muscle was allowed to stabilize for $5 \mathrm{~min}$ before new force measurements were made. In the force-frequency trials involving ryanodine, the muscle was equilibrated with $10 \mu \mathrm{moll}^{-1}$ ryanodine for 45 min prior to the onset of the trial. Muscles were allowed to recover at $1.0 \mathrm{~Hz}$ for $45 \mathrm{~min}$ between trials.

After the first experiments at $15^{\circ} \mathrm{C}$ and $25^{\circ} \mathrm{C}$, we noticed that the positive inotropic effect of adrenaline was deteriorating by the time a stimulation frequency of $1.0 \mathrm{~Hz}$ had been reached. This suggested either (1) a time-dependent desensitization with high adrenaline concentration, or (2) a frequency-dependent response to high adrenaline concentration. To test these possibilities, the order of application of stimulation frequency was changed for the $18{ }^{\circ} \mathrm{C}$ group and for half the $25^{\circ} \mathrm{C}$ group, such that frequency was increased from 1.0 to $3.5 \mathrm{~Hz}$ and then reduced to 0.2 and $0.5 \mathrm{~Hz}$.

To account for the slow deterioration of the preparation over the duration of the experiment, control and test trabeculae were dissected from the same heart, and control trabeculae were monitored in parallel with the test trabeculae in a separate organ bath. Control trabeculae were exposed to the same 
conditions of temperature, stimulation frequency and voltage as the test muscle but were only exposed to the low adrenaline concentrations throughout the force-frequency trials. Thus, changes in force development due to muscle fatigue were accounted for by subtracting the changes in force (as percentages of the initial tension generated) in controls from those for the experimental atria.

\section{Chemicals, calculations and statistical analyses}

All chemicals were purchased from Sigma (St Louis, MO, USA) with the exception of ryanodine, which was purchased from Calbiochem (San Diego, CA, USA). Force is expressed as $\mathrm{mN} \mathrm{mm}^{-2}$. Mean cross-sectional area was calculated using wet muscle mass, trabecular length and an assumed muscle density of $1.06 \mathrm{~g} \mathrm{~cm}^{-3}$ (Layland et al., 1995). Measurements of force, time to peak tension, time to $50 \%$ relaxation and rates $(\mathrm{d} f / \mathrm{d} t)$ of contraction and relaxation were achieved using the View II data analysis system (Gould, Cleveland, OH, USA). Significant increases after adrenaline stimulation and significant decreases after ryanodine treatment were assessed using one-way Student's $t$-tests $(P \leqslant 0.05)$.

\section{Results \\ Force-frequency effects \\ Temperature and frequency effects}

The yellowfin tuna atrium exhibits a biphasic forcefrequency response similar to that observed in skipjack tuna atrium (Keen et al., 1992), with a positive staircase at low frequencies $(0.2-0.5 \mathrm{~Hz})$ and a negative staircase within the more physiologically relevant frequency range (greater than $1.0 \mathrm{~Hz}$ ) (Fig. 1).

At $15^{\circ} \mathrm{C}$ and $18^{\circ} \mathrm{C}$, trabecular contractions often became irregular at frequencies greater than $2.0 \mathrm{~Hz}$ and $3.0 \mathrm{~Hz}$, respectively (denoted by the unconnected data points in Fig. 1). At $25^{\circ} \mathrm{C}$, however, the muscle could maintain regular contractions above $3.5 \mathrm{~Hz}$.

For most parameters measured, the individual variability at $18^{\circ} \mathrm{C}$ was less than that at both $15^{\circ} \mathrm{C}$ and $25^{\circ} \mathrm{C}$, which may be related to the fact that $18^{\circ} \mathrm{C}$ is the test temperature closest to the acclimation temperature of $20^{\circ} \mathrm{C}$.

\section{Effects of ryanodine}

Ryanodine significantly decreased force at all temperatures and at all pacing frequencies (Fig. 1). This indicates an active role for $\mathrm{SR} \mathrm{Ca}^{2+}$ release during excitation-contraction coupling in yellowfin tuna atrium that is to some extent independent of the contraction frequency and the temperature. Indeed, after ryanodine treatment, an equivalent level of force production to that obtained under control conditions could only be achieved at a lower pacing frequency. For example, force development under control conditions at $2.5 \mathrm{~Hz}$ and $18^{\circ} \mathrm{C}$ (lefthand panel in Fig. 1) was approximately $7 \mathrm{mN} \mathrm{mm}^{2}$; after ryanodine treatment, the same degree of force production could not be maintained at frequencies greater than $1.5 \mathrm{~Hz}$.

The degree of SR $\mathrm{Ca}^{2+}$ utilization also had a component that was both temperature- and frequency-dependent. The temperature-dependence of SR $\mathrm{Ca}^{2+}$ utilization was most evident at low pacing frequencies $(0.2-1.0 \mathrm{~Hz})$, where colder muscles were found to use less SR $\mathrm{Ca}^{2+}$ than warmer muscles (Fig. 2). No clear temperature-threshold for SR $\mathrm{Ca}^{2+}$-release channel function was observed over the range of temperatures tested. The response to ryanodine was frequency-dependent (Fig. 2) at $15^{\circ} \mathrm{C}$ and $18^{\circ} \mathrm{C}$, where $\mathrm{SR} \mathrm{Ca}^{2+}$ involvement increased as contraction frequency increased (non-parametric ANOVA, Kruskal-Wallis). At $25^{\circ} \mathrm{C}$, SR utilization was more or less constant over the physiological range of frequencies, but increased significantly at the highest frequencies. The greatest percentage decrease in force after ryanodine treatment occurred at the highest frequencies at all temperatures. This supports the suggestion of increased dependence on SR $\mathrm{Ca}^{2+}$ cycling during highfrequency contractions in yellowfin tuna heart muscle. In fact, at high frequencies, the temperature-dependency of the ryanodine response was almost abolished since the SR contribution approached or exceeded approximately $60 \%$ at all temperatures (Fig. 2).

\section{Effects of adrenaline}

No significant positive inotropic effect was observed at physiologically relevant frequencies when $1 \mu \mathrm{mol}{ }^{-1}$ adrenaline was applied to muscle pre-treated with ryanodine (Fig. 1). When the order of imposed frequency of stimulation was changed, such that frequency was increased from 1.0 to $3.5 \mathrm{~Hz}$ and then back to 0.2 and $0.5 \mathrm{~Hz}$ in the $18^{\circ} \mathrm{C}$ group, there were again no significant effects of adrenaline at any frequency. In the $25^{\circ} \mathrm{C}$ group, where the order of stimulation frequency was changed half-way through the experiments, there was a significant effect of adrenaline at only 0.2 and $0.5 \mathrm{~Hz}$ in the pooled groups. Thus, adrenergic stimulation did not overcome the negative effect of SR inhibition at physiological contraction frequencies in the atria of yellowfin tuna.

\section{Contraction kinetics}

\section{Temperature and frequency effects}

Contraction kinetics were temperature- and frequencydependent. The time to peak force and the time to $50 \%$ relaxation decreased as temperature and frequency increased (Fig. 3). The rates of contraction (Fig. 4) were not changed significantly by temperature, primarily because peak force itself decreased while the absolute time to peak force decreased with increasing temperature. The data suggest a slower rate of contraction at $18^{\circ} \mathrm{C}$ that at $15^{\circ} \mathrm{C}$; however, this was found not to be significant (Student's $t$-test, $P>0.05$ ), possibly because of the small sample size. We have no explanation for this trend. Rates of relaxation were also similar among temperatures (Fig. 4).

\section{Effects of ryanodine}

Ryanodine increased the absolute time required to reach peak tension (Fig. 3) and decreased the rate of contraction (Fig. 4), suggesting slower activation of the myofilaments in the absence of $\mathrm{SR} \mathrm{Ca}{ }^{2+}$ release. Similarly, the time to $50 \%$ relaxation increased (Fig. 3) and the rate of $50 \%$ relaxation 
Fig. 1. Force-frequency responses from yellowfin tuna atrial trabeculae at $15^{\circ} \mathrm{C}, 18^{\circ} \mathrm{C}$ and $25^{\circ} \mathrm{C}$ as indicated in the upper right-hand corner of each graph. The left-hand panel shows absolute values in $\mathrm{mN} \mathrm{m}^{-2}$ tissue. The right-hand panel shows data normalized to the control condition at $0.2 \mathrm{~Hz}$. Forcefrequency responses were obtained under different drug treatments, as indicated by the legend. Values are means \pm S.E.M.; $N=4$ at $15^{\circ} \mathrm{C}, N=4$ at $18^{\circ} \mathrm{C}$ and $N=8$ at $25^{\circ} \mathrm{C}$. Solitary points (not connected by lines) are values where $N$ is less than that stated above. *Significant $\quad(P<0.05)$ decreases with ryanodine (Ry); łsignificant increases with adrenaline (AD), determined using paired one-way Student's $t$-tests.

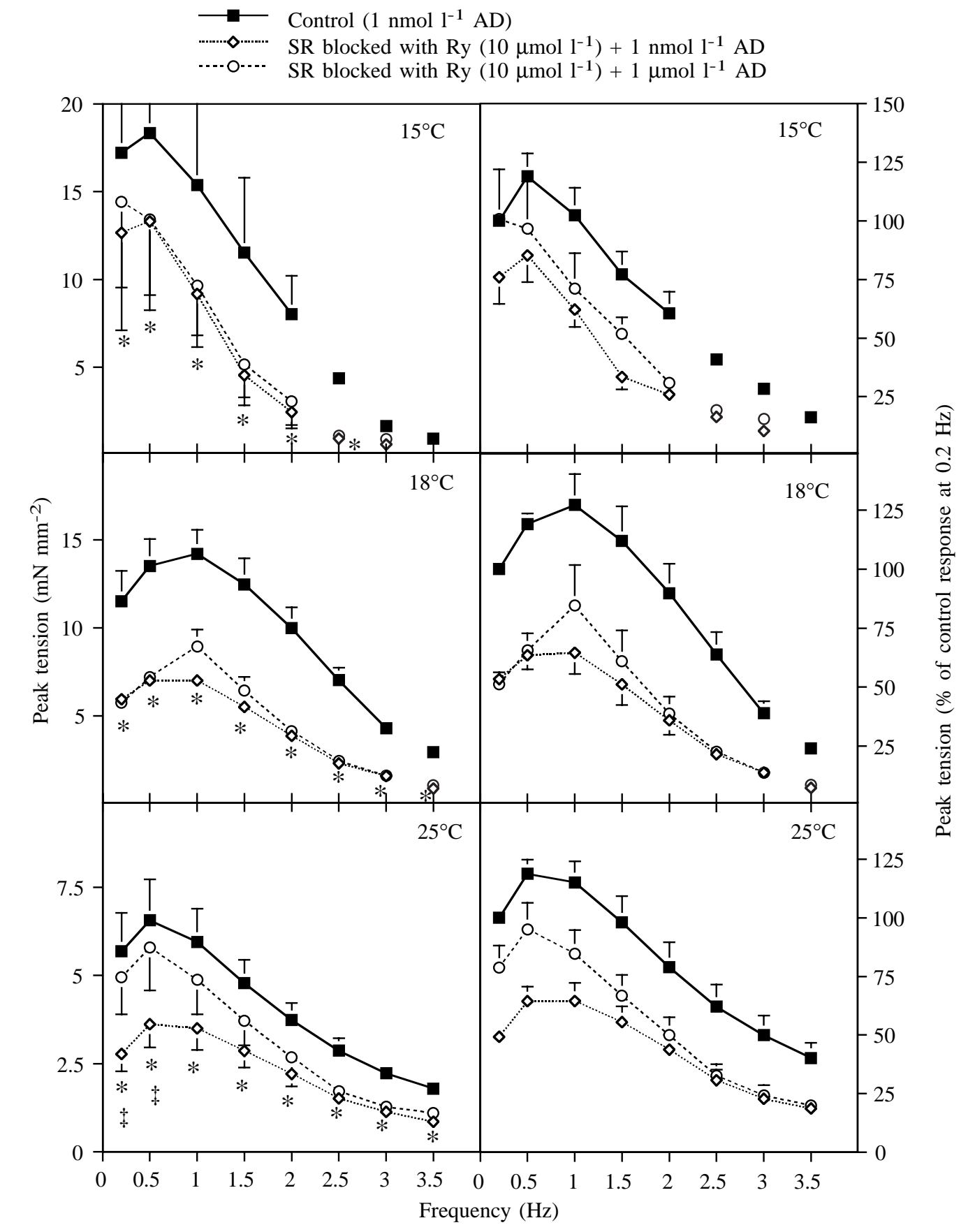

(Fig. 4) decreased after ryanodine treatment. This suggests that SR $\mathrm{Ca}^{2+}$ uptake, as well as release, is impaired in ryanodinetreated muscle. This would be expected if SR loading were compromised by the inability of the SR to release $\mathrm{Ca}^{2+}$ in the presence of a high $\left(10 \mu \mathrm{moll}^{-1}\right)$ ryanodine concentration. In all cases, the rates of contraction and relaxation never reach the pre-ryanodine-treated level at any contraction frequency.

\section{Discussion}

This is the first study to examine the relative importance of $\mathrm{SR} \mathrm{Ca}^{2+}$ cycling during force development in the atria of yellowfin tuna. Our results indicate that the SR can contribute up to $60 \%$ of the activator $\mathrm{Ca}^{2+}$ during force development at maximal contraction frequencies in the cardiac muscle of yellowfin tuna. This is the highest level of $\mathrm{SR} \mathrm{Ca}^{2+}$ involvement in force production reported for a teleost and is the first evidence directly linking the high heart rates of tuna with increased dependence on intracellular $\mathrm{Ca}^{2+}$ cycling. Freund and Block (1998 and in preparation) measured very large post-rest potentiations (a doubling of peak tension after a $20 \mathrm{~s}$ rest period) in yellowfin tuna ventricle, indicating that the SR contributes a significant amount of $\mathrm{Ca}^{2+}$ to both atrial and ventricular tissue. Further, their work revealed that Pacific 
Fig. 2. Percentage contribution of sarcolasmic reticulum (SR) $\mathrm{Ca}^{2+}$ to force development in atrial trabeculae from yellowfin tuna (YF) at $15^{\circ} \mathrm{C}, 18^{\circ} \mathrm{C}$ and $25^{\circ} \mathrm{C}$. Results were calculated as the percentage decrease in force from the control condition after ryanodine $\left(10 \mu \mathrm{moll}^{-1}\right)$ treatment at each frequency. Data for skipjack tuna (SJ) at $25^{\circ} \mathrm{C}$ (in the absence of adrenaline, AD) were calculated from the results of Keen et al. (1992). The two vertical dashed lines indicate the range of in vivo heart rates for free-swimming yellowfin tuna at $18^{\circ} \mathrm{C}$, and the two vertical dotted lines indicate the range of in vivo heart rates at $24^{\circ} \mathrm{C}$ (heart rate range taken from Korsmeyer et al., 1997). *Significant difference between the $25^{\circ} \mathrm{C}$ group and the other groups $\left(18\right.$ and $\left.15^{\circ} \mathrm{C}\right)$, tsignificant difference between the $15^{\circ} \mathrm{C}$ group and 18 and $25^{\circ} \mathrm{C}$ groups calculated using a non-parametric ANOVA (Kruskal-Wallis). Skipjack tuna data were not statistically compared with yellowfin tuna data. Values are means \pm S.E.M. (values of $N$ are as in Fig. 1).

mackerel (Scomber japonicus), a close phylogenetic relative of the yellowfin tuna, also demonstrates large ventricular post-rest potentiations, indicating that the large degree of SR utilization may not be limited to tuna, but rather may be a common trait of the Scombridae family.

Significant levels of SR $\mathrm{Ca}^{2+}$ involvement during force development have been demonstrated previously by Keen et al. (1992) for the skipjack tuna atrium. Their results indicate a maximum $30 \%$ decrease in peak force after ryanodine treatment at $2.5 \mathrm{~Hz}$ (these data are shown in Fig. 2 for comparison). A possible explanation for the greater response to ryanodine treatment in yellowfin compared with skipjack tuna may be related to tonic adrenergic stimulation. Fish hearts, including those of skipjack and yellowfin tuna (Keen et al., 1995), always have humoral adrenergic tonus in vivo, but most studies of cardiac tissue performance in vitro use saline without adrenaline as the control situation. Although we have no direct evidence, it is possible that, as a result of the absence of tonic adrenaline levels in the skipjack tuna study, sarcolemma $\mathrm{Ca}^{2+}$ influx was understimulated relative to the routine in vivo condition, which may alter SR $\mathrm{Ca}^{2+}$ loading and affect the response to ryanodine. In addition, the skipjack tuna were held and tested at $25^{\circ} \mathrm{C}$, but contraction frequency was not increased above $2.5 \mathrm{~Hz}$. On the basis of our results, if contraction frequency had been increased further, it might have resulted in greater SR involvement. However, the yellowfin tuna may simply have more $\mathrm{SR} \mathrm{Ca}^{2+}$ or utilize more $\mathrm{SR} \mathrm{Ca}^{2+}$ than the skipjack tuna. The yellowfin tuna (Thunnus) evolved more recently than the skipjack tuna (Katsuwonus) (Block et al., 1993), which suggests that SR utilization may be a phylogenetic correlate.

In most fish, SR Ca ${ }^{2+}$ utilization is low or absent (Driedzic and Gesser, 1988) and is only revealed under particular experimental conditions. For example, ryanodine abolishes

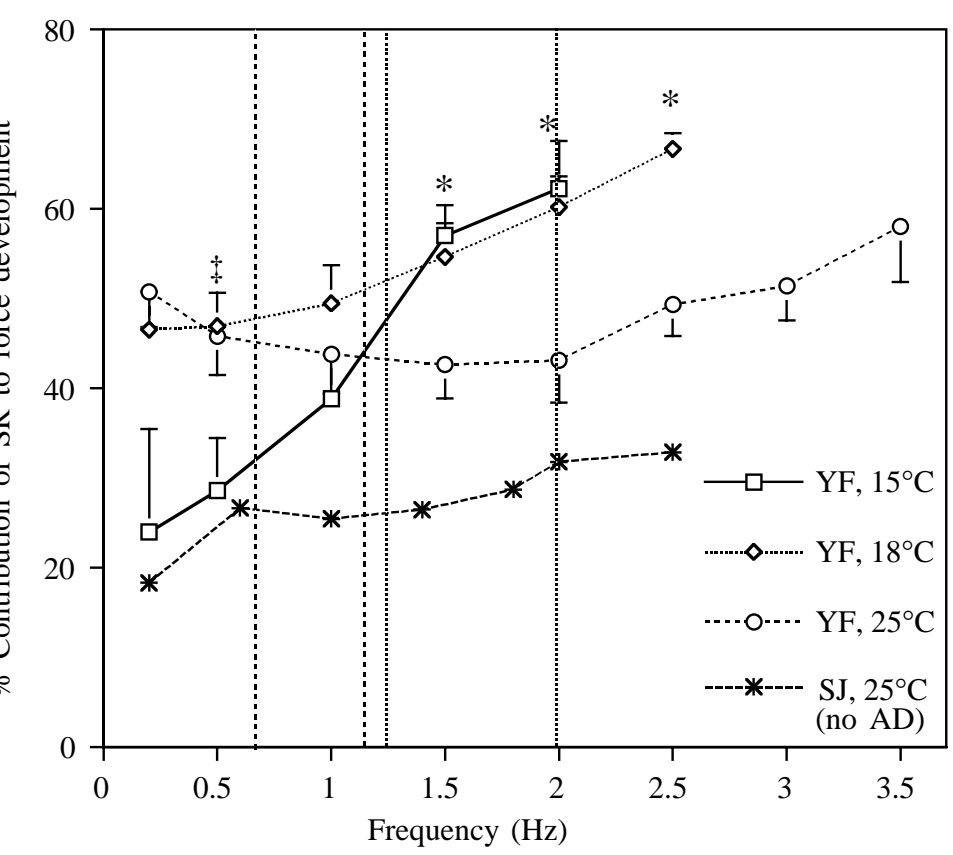

post-rest potentiations in trout ventricle (El-Sayed and Gesser, 1989; Møller-Nielsen and Gesser, 1992; Hove-Madsen, 1992). Furthermore, peak force in trout can be reduced by ryanodine either at subphysiological frequencies $(\leqslant 0.2 \mathrm{~Hz})$ (Keen et al., 1994; Gesser, 1996) or at temperatures $\left(>20^{\circ} \mathrm{C}\right)$ that exceed the thermal preference of the fish (Hove-Madsen, 1992; Shiels and Farrell, 1997). However, under normal physiological conditions of temperature and heart rate, $\mathrm{SR} \mathrm{Ca}{ }^{2+}$ cycling in most fish is negligible. Thus, the large degree of SR $\mathrm{Ca}^{2+}$ utilization in the yellowfin tuna atrium (present study), the yellowfin tuna ventricle (Freund and Block, 1998), the skipjack tuna atrium (Keen et al., 1992) and the pacific mackerel ventricle (E. V. Freund and B. A. Block, in preparation) differs from other fish studied to date. Studies of SR utilization in other members of the Scombridae family will be necessary to establish whether this trait is conserved throughout the scombrid phylogeny.

At low pacing frequencies, the temperature-dependency of $\mathrm{SR} \mathrm{Ca}^{2+}$ utilization in yellowfin tuna atrium is similar to that observed for trout ventricle, with a greater ryanodine response at warmer temperatures than at cooler temperatures (Figs 1,2). At low frequencies, muscles tested at $18{ }^{\circ} \mathrm{C}$ and $25^{\circ} \mathrm{C}$ utilized more $\mathrm{SR} \mathrm{Ca}^{2+}$ than those tested at $15^{\circ} \mathrm{C}$. However, within the physiologically relevant range of pacing frequencies (indicated by the vertical lines on Fig. 2), percentage SR $\mathrm{Ca}^{2+}$ utilization was greater at colder temperatures. This observation may have important ecophysiological implications. Tracking records of yellowfin tuna show that the fish spend the majority of their time within $8^{\circ} \mathrm{C}$ of the temperature of the surface water $(\mathrm{R} . \mathrm{W}$. Brill, B. A. Block, C. H. Boggs, K. A. Bigelow, E. V. Freund and D. J. Marcinek, in preparation; Holland et al., 1990; Block et al., 1997) (which is approximately $20^{\circ} \mathrm{C}$ off the coast of California). Thus, our acute temperature changes from the acclimation temperature of $20^{\circ} \mathrm{C}$ to either $15^{\circ}$ or $18^{\circ} \mathrm{C}$ 
Fig. 3. Time (s) required to reach peak tension (left-hand panel) and time (s) required to reach $50 \%$ relaxation (righthand panel) in paced atrial trabeculae from yellowfin tuna at three different temperatures. Note the change of scale in the bottom right-hand panel. Values are means \pm S.E.M. (values of $N$ are as in Fig. 1). All other details are as in Fig. 1.

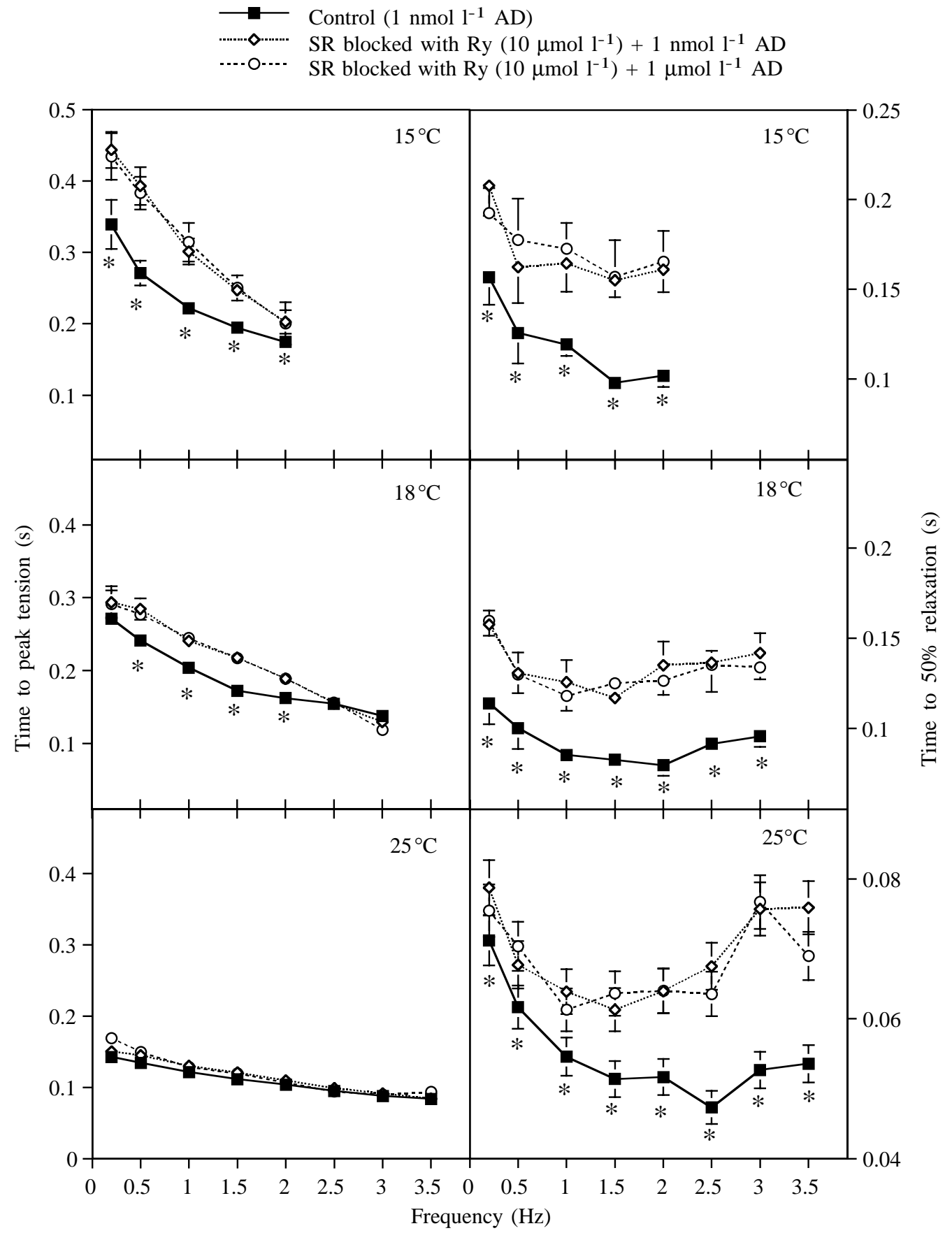

represent physiologically realistic temperature fluctuations that may be experienced when tuna dive in nature. The results of the present study show that $\mathrm{SR} \mathrm{Ca}^{2+}$ utilization for a given frequency within the physiological range is greater at 15 or $18^{\circ} \mathrm{C}$ than at $25^{\circ} \mathrm{C}$. This suggests that when yellowfin dive from $20^{\circ} \mathrm{C}$ into water at 18 or $15^{\circ} \mathrm{C}$ to forage (Holland et al., 1990; Block et al., 1997) they must increase their dependence on SR Ca ${ }^{2+}$ cycling to maintain a level of cardiac output similar to that at $25^{\circ} \mathrm{C}$. This may help to explain why the dive duration to cooler waters is usually short $(<30 \mathrm{~min})$ (R. W. Brill, personal communication). It is important to note that ryanodine binding is temperature-dependent in skeletal muscle, with lower binding affinity at colder temperatures (Ogawa and Harafuji, 1990). The temperature-dependence of ryanodine binding has not been examined in fish cardiac muscle; however, if the binding characteristics are similar to those of skeletal muscle, our results could underestimate $\mathrm{SR} \mathrm{Ca}^{2+}$ utilization at the colder temperatures.

As pacing frequency was increased to a maximum level, the temperature-dependency of the ryanodine response was reduced, and $\mathrm{SR} \mathrm{Ca}^{2+}$ utilization reached approximately $60 \%$ at all temperatures. Further, no clear temperature threshold for SR $\mathrm{Ca}^{2+}$-release channel function was observed over the range of temperatures used $\left(15,18\right.$ and $\left.25^{\circ} \mathrm{C}\right)$. Over a similar 
Fig. 4. Rates $(\mathrm{d} f / \mathrm{d} t)$ of contraction (left-hand panel) and of $50 \%$ relaxation (right-hand panel) in paced atrial trabeculae from yellowfin tuna at three different temperatures. Values are means \pm S.E.M. (values of $N$ are as in Fig. 1). All other details are as in Fig. 1.
Control (1 nmol 1-1 AD) $\begin{array}{cl}\cdots \cdots \cdots \cdot-\cdots \cdots \cdots & \text { SR blocked with Ry }\left(10 \mu \mathrm{mol} \mathrm{l}^{-1}\right)+1 \mathrm{nmol} \mathrm{l}^{-1} \mathrm{AD} \\ \cdots \cdot-\mathrm{O}^{-\cdots-} & \text { SR blocked with Ry }\left(10 \mu \mathrm{mol} \mathrm{l}^{-1}\right)+1 \mu \mathrm{mol} \mathrm{l^{-1 }} \mathrm{AD}\end{array}$

$\begin{array}{cl}\cdots \cdots \cdots \cdots \cdots \cdots & \text { SR blocked with Ry }\left(10 \mu \mathrm{mol} \mathrm{l}^{-1}\right)+1 \mathrm{nmol} \mathrm{l}^{-1} \mathrm{AD} \\ \cdots & \text { SR blocked with Ry }\left(10 \mu \mathrm{mol} \mathrm{l}^{-1}\right)+1 \mu \mathrm{mol} \mathrm{l} \mathrm{l}^{-1} \mathrm{AD}\end{array}$

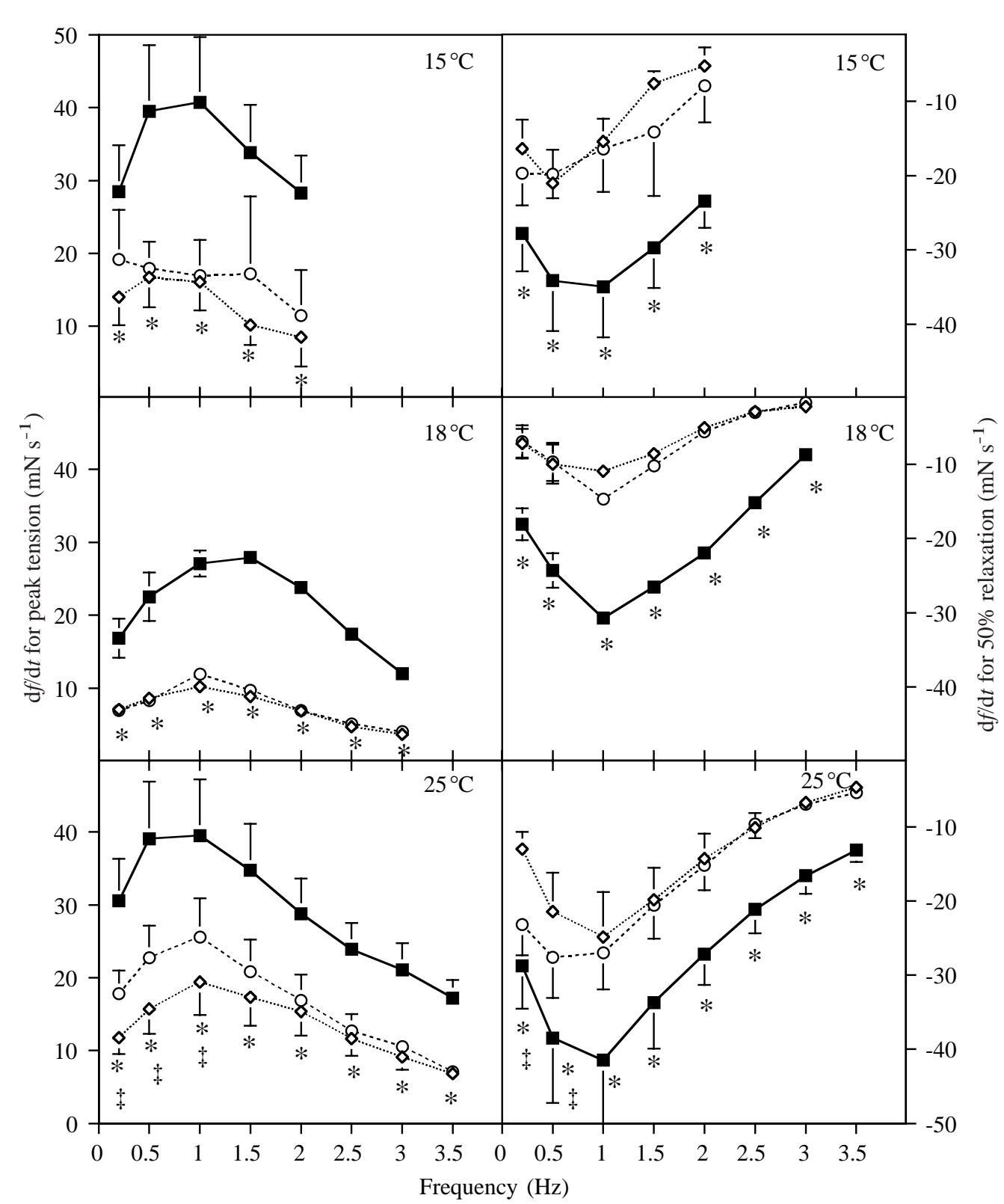

range of temperatures in rainbow trout ventricle, SR utilization varied greatly. Significant $\mathrm{SR} \mathrm{Ca}^{2+}$ utilization occurred at $22^{\circ} \mathrm{C}$ at physiologically relevant contraction frequencies (Shiels and Farrell, 1997), but at $18^{\circ} \mathrm{C}, \mathrm{SR} \mathrm{Ca}^{2+}$ utilization was limited to low-frequency contractions (Keen et al., 1994); below $15^{\circ} \mathrm{C}, \mathrm{SR} \mathrm{Ca}^{2+}$ utilization was nonexistent (El-Sayed and Gesser, 1998; Møller Nielsen and Gesser, 1992; Keen et al., 1994). Despite the possible differences in the degree of SR development in fish atrium versus fish ventricle, the degree of $\mathrm{SR} \mathrm{Ca}^{2+}$ utilization reported here for tuna atrial muscle is the highest ever reported for a fish. Thus, yellowfin tuna differ from most fish studied to date in both the temperature- and frequencydependent responses to ryanodine.

To obtain a more integrative perspective on the effects of ryanodine on heart function in yellowfin tuna, we calculated the pumping capacity of the muscle at each temperature (Fig. 5). Cardiac pumping capacity, the product of pacing rate and peak force (Matikainen and Vornanen, 1992; Shiels and Farrell, 1997), can be used as an index of power output for isolated muscle preparations since it integrates the effects of changes in force and changes in stimulation frequency. Moreover, the peak of the pumping capacity versus frequency curve suggests an optimum frequency for pumping capacity or 

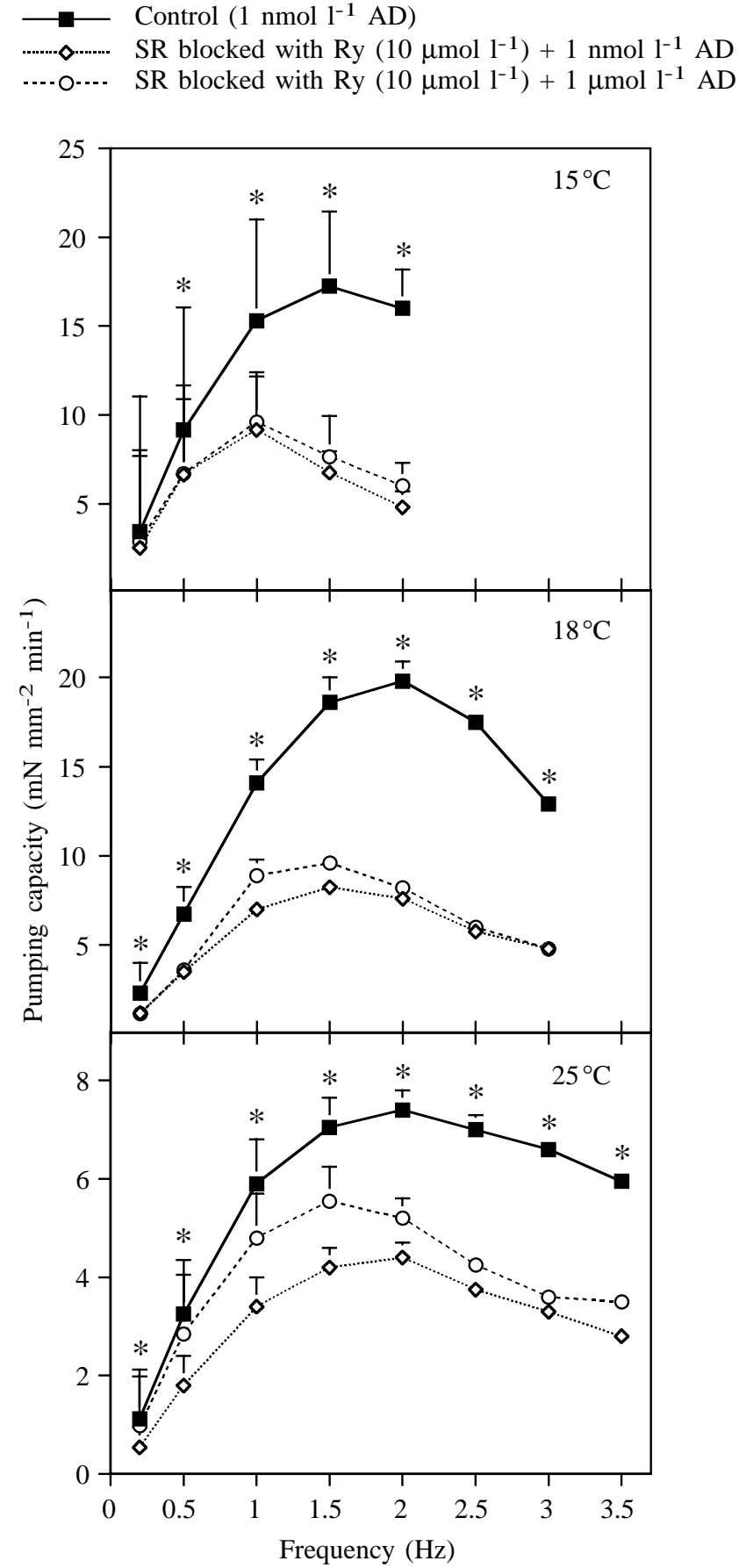

Fig. 5. Pumping capacity (the product of frequency and peak force) calculated for isolated atrial trabeculae from yellowfin tuna at three different temperatures. Note that the scale at $25^{\circ} \mathrm{C}$ is different from than that at 15 and $18^{\circ} \mathrm{C}$. Values are means \pm S.E.M. (values of $N$ are as in Fig. 1). *Significant decrease with ryanodine application, using one-tail Student's $t$-test. All other details are as in Fig. 1.

'power output'. The optimum frequency for pumping capacity in yellowfin tuna atrium was approximately $2 \mathrm{~Hz}$ at 18 and $25^{\circ} \mathrm{C}$, and approximately $1.5 \mathrm{~Hz}$ at $15^{\circ} \mathrm{C}$ (Fig. 5). In vivo heart rate measurements from yellowfin tuna range from approximately 0.6 to $1.3 \mathrm{~Hz}$ at $18^{\circ} \mathrm{C}$ and approximately 1.3 to
$2.0 \mathrm{~Hz}$ at $24^{\circ} \mathrm{C}$ (measured while the fish swam in a swim tunnel; Korsmeyer et al., 1997) to approximately $1.8 \mathrm{~Hz}$ at $25{ }^{\circ} \mathrm{C}$ (measured in free-swimming fish; Jones et al., 1993) (no data are available for $15^{\circ} \mathrm{C}$ ). Thus, the optimum frequency for pumping capacity calculated from our study falls within the upper range of actual in vivo contraction frequencies.

Ryanodine decreases the pumping ability of the yellowfin tuna atrium at all temperatures and pacing frequencies, as anticipated from the peak force data. Clearly, this is related to the slower rates of tension development and relaxation in the presence of ryanodine. Moreover, ryanodine shifts the optimum frequency for 'power output' downwards and to the left. This is especially evident at 15 and $18^{\circ} \mathrm{C}$, where the frequency-dependence of the ryanodine response is accentuated. The reduction in optimal stimulation frequency after ryanodine treatment in yellowfin tuna atrium is similar, but more pronounced, than that observed in isolated rainbow trout ventricular trabeculae at $22{ }^{\circ} \mathrm{C}$ both contracting isometrically (Shiels and Farrell, 1997) and performing workloops (Shiels et al., 1998). Thus, the inotropic and chronotropic pumping abilities of the yellowfin atrium are impaired when $\mathrm{SR} \mathrm{Ca}^{2+}$ release is inhibited with ryanodine, providing further evidence that $\mathrm{SR} \mathrm{Ca}^{2+}$ delivery is necessary during highfrequency contractions in yellowfin tuna. This will have considerable physiological importance since tuna modulate their cardiac output (the volume of blood pumped per unit time) primarily through changes in heart rate (Farrell, 1996; Korsmeyer et al., 1997), whereas most teleosts regulate their cardiac output via changes in stroke volume (the volume of blood pumped per beat).

In fish, activator $\mathrm{Ca}^{2+}$ can arrive at the myofilaments via both the SR and the sarcolemma, with the proportion of $\mathrm{Ca}^{2+}$ from each source varying with species, temperature and cardiac frequency. Sarcolemma $\mathrm{Ca}^{2+}$ flux is normally modulated to a significant extent by adrenergic stimulation. In fact, studies with rainbow trout show that, even under conditions where the SR is significantly involved in excitation-contraction coupling, increasing sarcolemma $\mathrm{Ca}^{2+}$ influx in response to adrenergic stimulation can ameliorate any negative effect of ryanodine on force production (Shiels and Farrell, 1997). This suggests that the relative importance of the contribution of the SR is easily overshadowed by increased sarcolemma $\mathrm{Ca}^{2+}$ flux in situations where cardiac tissue is stimulated by adrenaline. This was not the case in yellowfin tuna. High doses of adrenaline did not ameliorate the negative inotropic effects of ryanodine. This was surprising because preliminary studies had suggested that yellowfin tuna atria are responsive to adrenergic stimulation and because isolated trabeculae from skipjack tuna show dose-dependent inotropic responses to adrenaline in the absence of ryanodine (Keen et al., 1992). However, as for yellowfin tuna, ryanodine-treated atrial trabeculae from skipjack tuna were also unresponsive to adrenergic stimulation (H. A. Shiels, unpublished observations). The lack of a positive inotropic response to adrenaline after ryanodine treatment in the yellowfin and skipjack tuna may be related to the mechanism of action of adrenaline. In general, 
$\beta$-adrenoceptor agonists increase sarcolemma $\mathrm{Ca}^{2+}$ flux by initiating the cAMP second messenger cascade (Lefkowitz et al., 1983), which culminates in phosphorylation of the L-type $\mathrm{Ca}^{2+}$ channel, increasing its open probability. Recently, increased $\mathrm{Ca}^{2+}$ influx through L-type $\mathrm{Ca}^{2+}$ channels in response to adrenergic stimulation has been demonstrated in patchclamped trout and carp Cyprinus carpio cardiac myocytes (Vornanen, 1997, 1998). In mammals, however, an additional positive inotropic (and chronotropic) adrenergic mechanism involves the cAMP-dependent and $\mathrm{Ca}^{2+}$-calmodulin-dependent protein-kinase-mediated phosphorylation of phospholamban, an integral membrane protein of cardiac SR (Koss and Kranias, 1996). It has been suggested that phospholamban is involved in mediating the relaxant and inotropic effects of $\beta$-agonists in the heart by increasing the efficacy of the SR $\mathrm{Ca}^{2+}$-ATPase (Talosi et al., 1993). An increase in the activity of the SR $\mathrm{Ca}^{2+}$-ATPase would lead to increased $\mathrm{SR} \mathrm{Ca}^{2+}$ loading during the diastolic interval, which makes more $\mathrm{Ca}^{2+}$ available for subsequent contractions and leads to increased contractile force (i.e. positive inotropy) (Koss and Kranias, 1996). To our knowledge, the presence or absence of phospholamban has yet to be established for fish. However, if phospholamban is present in the tuna heart, the possibility exists that the positive inotropic response to adrenergic stimulation in tuna is mediated, at least in part, via phospholamban at the level of the SR. This mechanism would then explain the lack of an adrenergic effect after ryanodine incubation in yellowfin atrium.

Adrenergic desensitization could also account for the inability of adrenaline to offset the effects ryanodine. To test this possibility, we tested low frequencies $(0.2$ and $0.5 \mathrm{~Hz})$ at the end of the force-frequency trial in the $18^{\circ} \mathrm{C}$ group and in half the $25^{\circ} \mathrm{C}$ group. There was no significant increase in tension at $1.0 \mathrm{~Hz}$ at 18 and $25^{\circ} \mathrm{C}$, suggesting that adrenergic desensitization over the course of the experiment is minor. Rather, it appears that, in the yellowfin atrial muscle, adrenaline is less able to overcome the effects of ryanodine, especially when compared with trout. Indeed, Keen et al. (1995) suggest that the yellowfin tuna myocardium is less responsive to adrenergic antagonists than that of most other fish studied to date. In agreement with this suggestion, high levels of extracellular $\mathrm{Ca}^{2+}$ (which could mimic the effects of adrenergic stimulation on the sarcolemma L-type $\mathrm{Ca}^{2+}$ channel) do not increase force in the ventricular trabeculae of yellowfin tuna at high frequencies (Freund et al., 1996). In contrast, Driedzic and Gesser (1985) have demonstrated that high extracellular $\left[\mathrm{Ca}^{2+}\right]$ ameliorated the negative effects of high pacing frequency in isolated cod Gadus morhua hearts. Again, this suggests a fundamental difference in $\mathrm{Ca}^{2+}$ cycling between tuna and other teleosts.

Studies of tuna physiology have revealed differences between tuna and other teleosts in such characteristics as standard metabolic rate, gill morphology and cardiac performance (Brill, 1996; Farrell, 1996). We have shown that the yellowfin tuna atrium routinely utilizes $\mathrm{SR} \mathrm{Ca}^{2+}$ during force development, with the degree of SR involvement being both temperature- and frequency-dependent. Further, we find that the percentage of $\mathrm{SR} \mathrm{Ca}^{2+}$ utilization increases with increased cardiac frequency, and suggest that this ability to utilize SR $\mathrm{Ca}^{2+}$ cycling to deliver and remove $\mathrm{Ca}^{2+}$ from the myofilaments allows yellowfin tuna to increase the maximum contraction frequency of their cardiac muscle beyond those of most other fish. These results, in conjunction with those of Keen et al. (1992) and Freund and Block (1998), again suggest that tuna differ from other fishes in their ability routinely to utilize SR $\mathrm{Ca}^{2+}$. Indeed, that Pacific mackerel also demonstrate routine SR $\mathrm{Ca}^{2+}$ utilization (Freund and Block, 1998) may indicate that it is not tuna per se, but rather the family Scombridae, that are unique in their ability to utilize SR $\mathrm{Ca}^{2+}$. Further studies with other scombrid fishes would be necessary to test this hypothesis.

We would like to thank everyone at Hopkins Marine Station and the Monterey Bay Aquarium for their help with the tuna. We would also like to thank Seana Buchanan for her help in analyzing the data. This research was supported through a NSERC research grant to A.P.F., an NSERC graduate fellowship to H.A.S. and an NSF grant to B.A.B.

\section{References}

Altringham, J. D. and Block, B. A. (1997). Why do tuna maintain elevated slow muscle temperatures? Power output of muscle isolated from endothermic and ectothermic fish. J. Exp. Biol. 200, 2617-2697.

Bers, D. M. (1987). Ryanodine and the $\mathrm{Ca}^{2+}$ content of the SR assessed by caffeine and rapid cooling contractures. Am. J. Physiol. 253, C408-C415.

Bers, D. M. (1989). SR Ca ${ }^{2+}$ loading in cardiac muscle preparations based on rapid cooling contractures. Am. J. Physiol. 256, C109-C120.

Bers, D. M. (1991). Excitation-Contraction Coupling and Cardiac Contractile Force. London: Kluwer, Academic Publisher.

Black, E. C. (1953). Upper lethal temperatures of some British Columbian freshwater fishes. J. Fish. Res. Bd Can. 10, 196-210.

Block, B. A., Finnerty, J. R., Stewart, A. F. R. and Kidd, J. (1993). Evolution of endothermy in fish: mapping physiological traits on a molecular phylogeny. Science 260, 210-214.

Block, B. A., Keen, J. E., Castillo, B., Dewar, H., Freund, E. V., Marcinek, D. J. and Farwell, C. (1997). Environmental preferences of yellowfin tuna at the northern extent of their range. Mar. Biol. 130, 119-132.

Brill, R. W. (1987). On the standard metabolic rates of tropical tuna, including the effect of body size and acute temperature change. Fishery Bull. Fish Wldl. Serv. U.S. 85, 25-35.

Brill, R. W. (1996). Selective advantages conferred by the high performance physiology of tuna, billfishes and dolphin fish. Comp. Biochem. Physiol. 113A, 3-15.

Davie, P. S. and Farrell, A. P. (1991). Cardiac performance of an isolated heart preparation from the dogfish (Squalaus acanthias): The effects of hypoxia and coronary artery perfusion. Can. J. Zool. 69, 1822-1828.

Driedzic, W. R. and Gesser, H. (1985). $\mathrm{Ca}^{2+}$ protection from the negative inotropic effect of contraction frequency on teleost hearts. J. Comp. Physiol. B 156, 135-142. 
Driedzic, W. R. and Gesser, H. (1988). Differences in force-frequency relationships and $\mathrm{Ca}^{2+}$ dependency between elasmobranchs and teleost hearts. J. Exp. Biol. 140, 227-241.

El-Sayed, M. F. and Gesser, H. (1989). Sarcoplasmic reticulum, potassium and cardiac force in rainbow trout and plaice. Am. J. Physiol. 257, R599-R604.

Farrell, A. P. (1991). From hagfish to tuna - a perspective on cardiac function. Physiol. Zool. 64, 1137-1164.

Farrell, A. P. (1996). Features heightening cardiovascular performance in fishes, with special reference to tuna. Comp. Biochem. Physiol. 113A, 61-67.

Farrell, A. P., Davie, P. S., Franklin, C. E., Johansen, J. A. and Brill, R. W. (1992). Cardiac physiology in tuna. I. In vitro pefused heart preparations from yellowfin and skipjack tuna. Can. J. Zool. 70, 1200-1210.

Farrell, A. P., MacLeod, K. R. and Chancey, B. (1986). Intrinsic mechanical properties of the perfused rainbow trout heart and the effects of catecholamines and extracellular $\mathrm{Ca}^{2+}$ under control and acidotic conditions. J. Exp. Biol. 125, 319-345.

Freund, E. V. and Block, B. A. (1998). Increased temperature causes decreased force production in ventricular strips of endothermic and ectothermic scombrids. Am. Zool. 37, 187A.

Freund, E. V., Harwood, C. L., Altringham, J. D. and Block, B. A. (1996). Force-frequency relationships in ventricular strips of three scombrid fishes and effects of changes in extracellular $\mathrm{Ca}^{2+}$ and temperature. Am. Zool. 36, 66A.

Gesser, H. (1996). Cardiac force-interval relationship, adrenaline and sarcoplasmic reticulum in rainbow trout. J. Comp. Physiol. B 166, 278-285.

Graham, M. S. and Farrell, A. P. (1989). The effect of temperature acclimation and adrenaline on the performance of a perfused trout heart. Physiol. Zool. 62, 38-61.

Holland, K. N., Brill, R. W. and Chang, R. K. C. (1990). Horizontal and vertical movements of yellowfin and bigeye tuna associated with fish aggregating devices. Fishery Bull. Fish Wildl. Serv. US 88, 493-507.

Hove-Madsen, L. (1992). The influence of temperature on ryanodine sensitivity and the force-frequency relationship in the myocardium of rainbow trout. J. Exp. Biol. 167, 47-60.

Jones, D. R., Brill, R. W. and Bushnell, P. G. (1993). Ventricle and arterial dynamics of anaesthetised and swimming tuna. J. Exp. Biol. 182, 97-112.

Keen, J. E., Aota, S., Brill, R. W., Farrell, A. P. and Randall, D. J. (1995). Cholinergic and adrenergic regulation of heart rate and ventral aortic pressure in two species of tropical tuna, Katsuwonus pelamis and Thunnus albacares. Can. J. Zool. 73, 1681-1688.

Keen, J. E., Farrell, A. P., Tibbits, G. F. and Brill, R. W. (1992). Cardiac physiology in tuna. II. Effect of ryanodine, $\mathrm{Ca}^{2+}$ and adrenaline on force-frequency relationships in atrial strips from skipjack tuna, Katsuwonus pelamis. Can. J. Zool. 70, 1211-1217.

Keen, J. E., Viazon, D.-M., Farrell, A. P. and Tibbits, G. F. (1994). Effect of temperature and temperature acclimation on the ryanodine sensitivity of the trout myocardium. J. Comp. Physiol. B 164, $438-443$.
Korsmeyer, K. E., Chin, N. L., Shadwick, R. E. and Graham, J. B. (1997). Heart rate and stroke volume contributions to cardiac output in swimming yellowfin tuna: response to exercise and temperature. J. Exp. Biol. 200, 1975-1986.

Koss, K. L. and Kranias, E. G. (1996). Phospholamban: a prominent regulator of myocardial contractility. Circulation Res. 79, 1059-1063.

Layland, J., Young, I. S. and Altringham, J. D. (1995). The effect of cycle frequency on the power output of rat papillary muscle in vitro. J. Exp. Biol. 198, 1035-1043.

Lefkowitz, R. J., Stadel, J. M. and Caron, M. G. (1983). Adenylate cyclase coupled $\beta$-adrenergic receptors: structure and mechanism of activation and desensitization. Annu. Rev. Biochem. 52, 159-186.

Matikainen, N. and Vornanen, M. (1992). Effect of season and temperature acclimation on the function of crucian carp (Carassius carassius) heart. J. Exp. Biol. 167, 203-220.

Milligan, C. L., Graham, M. S. and Farrell, A. P. (1989). The response of trout red cells to adrenaline during seasonal acclimation and changes in temperature. J. Fish Biol. 35, 229-236.

Møller-Nielsen T. and Gesser, H. (1992). Sarcoplasmic reticulum and excitation-contraction coupling at $20^{\circ} \mathrm{C}$ and $10^{\circ} \mathrm{C}$ in rainbow trout myocardium. J. Comp. Physiol. B 162, 526-534.

Ogawa, Y. and Harafuji, H. (1990). Effect of temperature on $\left[{ }^{3} \mathrm{H}\right]$ ryanodine binding to sarcoplasmic reticulum from bullfrog skeletal muscle. J. Biochem. 107, 887-893.

Rousseau, E., Smith, J. S. and Meissner, G. (1987). Ryanodine modifies conductance and gating behaviour of single $\mathrm{Ca}^{2+}$ release channels. Am. J. Physiol. 253, C364-C368.

Shiels, H. A. and Farrell, A. P. (1997). The effect of temperature and adrenaline on the relative importance of the sarcoplasmic reticulum in contributing $\mathrm{Ca}^{2+}$ to force development in isolated ventricular trabeculae from rainbow trout. J. Exp. Biol. 200, 1607-1621.

Shiels, H. A., Stevens, E. D. and Farrell, A. P. (1998). Effect of temperature, adrenaline and ryanodine on power production in trout (Oncorhynchus mykiss) ventricular trabeculae. J. Exp. Biol. 201, 2701-2710.

Sitsapesan, R., Montgomery, R. A. P., MacLeod, K. T. and Williams, A. J. (1991). Sheep cardiac sarcoplasmic reticulum $\mathrm{Ca}^{2+}$ release channels: modifications of conductance and gating by temperature. J Physiol., Lond. 434, 469-488.

Talosi, L., Edes, I. and Kranias, E. G. (1993). Intracellular mechanisms mediating reversal of $\beta$-adrenergic stimulation in intact beating hearts. Am. J. Physiol. 264, H791-H797.

Tibbits, G. F., Moyes, C. D. and Hove-Madsen, L. (1992). Excitation-contraction coupling in the teleost heart. In Fish Physiology (ed. W. S. Hoar, D. J. Randall and A. P. Farrell), pp. 267-296. New York: Academic Press.

Vornanen, M. (1997). Sarcolemmal Ca influx through L-type Ca channels in the ventricular myocytes of a teleost fish. Am. J. Physiol. 272, 1432-1440.

Vornanen, M. (1998). L-type $\mathrm{Ca}^{2+}$ current in fish cardiac myocytes: effects of thermal acclimation and $\beta$-adrenergic stimulation. J. Exp. Biol. 201, 533-547. 